\title{
Training System for Innovative Talents Based on the Mode of Technical Assistant
}

\author{
Aijun Tang ${ }^{1}$ Hailong $\mathrm{Ma}^{2}$ Bin $\mathrm{Xu}^{2}$ Xingdong Yuan ${ }^{2}$ \\ ${ }^{1}$ School of Mechanical and Electronic Engineering in Shangdong Jianzhu University, \\ Jinan, Shandong Province, China \\ ${ }^{2}$ College of Materials Science and Engineering in Shangdong Jianzhu University, Jinan, \\ Shandong Province, China
}

\begin{abstract}
Based on the exploratory practice for years in the major of Mechanical and Electronic Engineering in Shandong Jianzhu University and the innovative practical base, this paper detailed describes the talents training mode of technical assistant in the running mechanism and comprehensive qualities. Hence, this training mode can effectively solve the poor practical ability in the experimental teaching to improve students' innovative abilities.
\end{abstract}

Keywords: Innovative practical base; Technical assistant; Innovative ability training

\section{Introduction}

Economic globalization is the age trend of economic development since 21th century. Globe marketization and economic globalization must bring about the educational internationalization $[1,2]$. The international competition focuses on the competition of talents strength. As supporting the economic development, higher engineering education should train the undergraduates' innovative and practical abilities, and enhance the training of innovative quality $[3,4]$.

Shangdong Jianzhu University is one of the provincial universities and colleges, in which engineering is given priority and multi-disciplinary are coordinated development. This university trains the application talents of having innovation spirit and practical ability, which pay attention of theory with practice and push the reforms of teaching content, course system and practical teaching. Integrating the own characteristic, this university constructs the "three-dimensional practice" teaching system, which makes the platform of experimental teaching, practical teaching and technological innovation activities for the personality development of undergraduates. This system improves the talent training quality and enhances the application ability of technological innovation and practice of undergraduates.

\section{Operation mechanism of technical assistant}

\subsection{Rely on the professional laboratory to establish the innovative practice base}

The School of Mechanical and Electronic Engineering established the mechanical processing base for innovation practice based on the mechanical engineering experimental teaching center. The construction principle is "mechanism has full freedom, time leaves some leeway, space has enough area". The mode is long-term training of technical assistant, together with short-term skill training of 
interesting. The base always implements the teaching idea of "laying a solid foundation, carrying out the comprehensive practice, having the courage to innovation, developing the personality". The operation mechanism fundamentally changed the traditional idea that experiment teaching depending the theory teaching, which improved the students' ability of solving engineering problems with the modern science and technology.

\subsection{Innovative talents training mode in the innovation practice base}

The innovation practice base carries out the idea of "process cultivate talent", and established the perfect implementation process. The base trained the practical and innovative abilities by the mode of technical assistant, and established the complete implementation process in the recruitment, selection, training, promotion and exit of the technical assistant. Aim at the specialty students who interesting the research projects, the base trained them according to the science and technology assistant training mode. Firstly, the students must go through the basic study. Secondly, the students do the projects into the base team. Then, the students can host some small topic. Finally, the students can join the teachers' practical research projects. After training, the technical assistant can independently accomplish the declaration, implementation and examination of the project.

\section{The comprehensive training system of technical assistant}

\subsection{The recruitment process of technical assistant}

The base recruits the technological assistant in autumn and spring, in which the freshmen is $5 \%$, the sophomore is
$25 \%$, the junior is $70 \%$. The base recruits the excellent students to develop innovative practice, and gradually formed the features training mode of recruiting outstanding undergraduate as "technological assistant". The flow diagram of recruiting is shown as Fig.1.

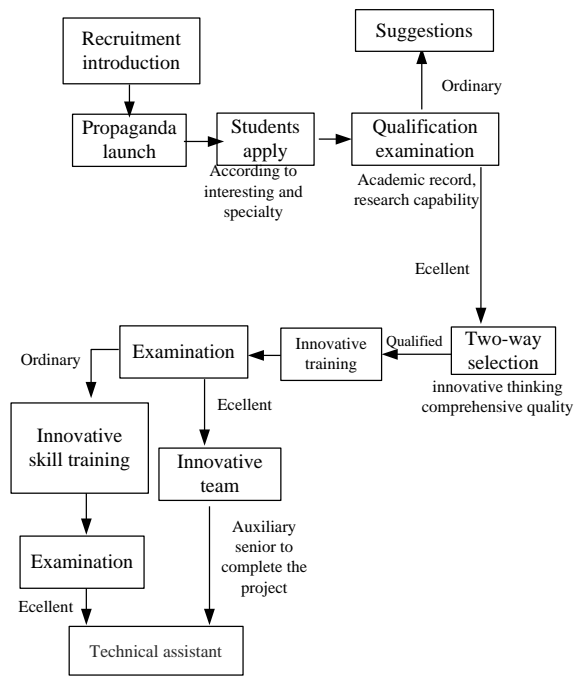

Fig. 1: The flow diagram of recruiting.

\subsection{Training process of technical assistant}

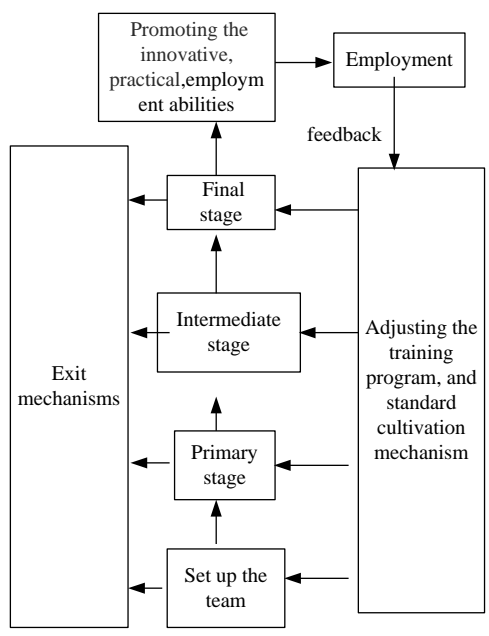

Fig. 2: The flow diagram of training the technical assistant. 
The recruited students must go through the strict examination and different training. One kind is the short-term training by the teachers and technical assistants to master the advanced modern software, modern design method. The other kind is long-term training. The technical assistants can study for one to two years in the teachers' projects, who auxiliary senior to complete the project, directly involved in scientific research projects, independently completed the research projects. The flow diagram of training the technical assistant is shown as Fig.2.

\subsection{Training system of comprehendsive qualities for technical assistant}

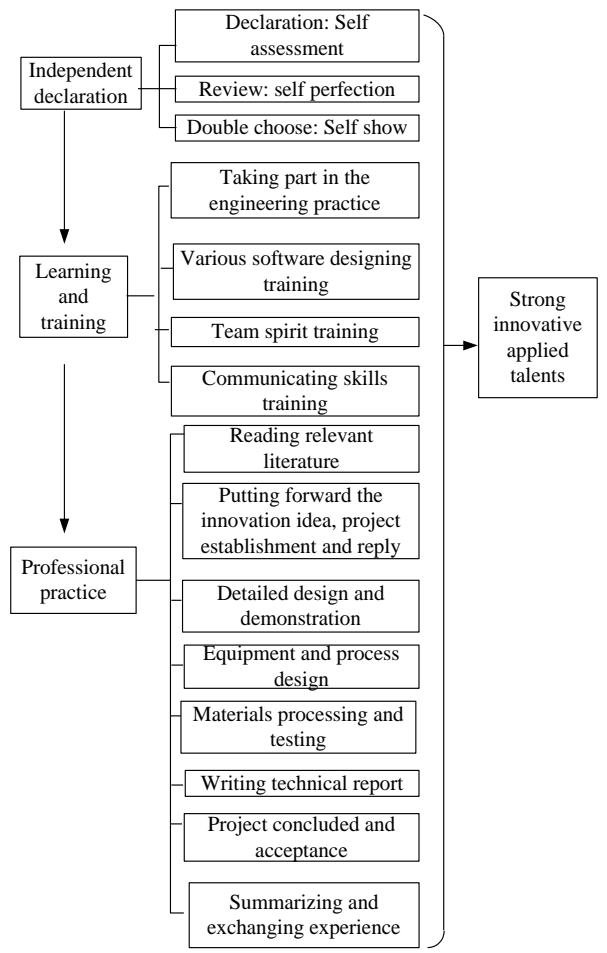

Fig. 3: Comprehensive quality training system of technological assistant.

The technological activities flow of base is constituted by simulating the implementation measures of project and scientific research projects from proposing and setting up projects to the implementing and accepting projects. Through the links of public demonstration and reply to an argument, we can realize the radiation effects of base training mode. The comprehensive quality training system of technological assistant is shown as Fig.3.

\section{Effect of technical assistant}

\subsection{Promoting the undergraduates' employment competition}

The base cultivates the undergraduates' innovation practical ability by the technological assistant mode. It gradually forms the autonomic and inquiry learning mode, which is harmony between the teachers and undergraduates, between the senior and junior in different major. This mode can ensure the undergraduates to find their characteristics of practical content. The technological assistants must guide three external-base undergraduates to learn professional knowledge, participate in technological innovation activities, which amplify the training mode of the base. This mode drives the more undergraduates to participate in professional study and technological practical activities, which promote the study style construction to steady development. For seven years, 94\% undergraduates of this major participated in the technological innovation activities, and the undergraduates' employment remain above $90 \%$, and passed the entrance exams for postgraduates is $20 \%$, and the employment quality increased year by year.

\subsection{Improving the undergraduates' engineering quality and practical skills}

Through strengthening the combination 
degree of experimental teaching, scientific research and engineering practice, we introduce the latest achievements and the latest technology into the experimental teaching, which raised the undergraduates' practical skills and engineering quality. Undergraduates of this major won numerous awards in Mechanical and Electrical Products Innovation Competition in Shandong. Undergraduates of this major were awarded numerous in Comprehensive Ability of Engineering Training Competition.

\subsection{Increasing the undergraduates' innovation practical ability and winning numerous awards in various competition}

Undergraduates' innovative, creative and understanding abilities have been increased. In the curriculum and graduation designs in recent years, the undergraduates' practical ability and designing thinking have a significant progress. Moreover, some undergraduates consulted the teachers some problems of engineering problems encountered. The training mode of "technological assistant" has subtly influenced students learning. Undergraduates in extracurricular technology series competitions have achieved remarkable results. In the recent three years, undergraduates of this major successively received five items national prizes and 22 items provincial awards in the "Challenge Cup" series competition. Undergraduates published 2 piece EI papers with the first author, and authorized 1 item national inventive patent and 9 items utility model patents. Undergraduates won 1 item the national special-class award, 1 item the national first award, 3 items the national third awards in the 11th "Challenge Cup" national university extracurricular technology competition.

\section{Conclusion}

Through the scientific activity system, the training mode of technical assistants established the complete implementation process from the recruitment, selection, training, promotion, exit mechanism for the technical assistants. It is effective to solve the poor theoretical basis, the weak engineering practice ability and the scarce innovative ability, which enhanced the students' practical and innovative ability.

\section{Acknowledgments}

This work was financially supported by Shandong Province Graduate Education Innovative Projects (SDYY11063).

\section{References}

[1] JianGuo Liu, ZhiXin Liu. Educational Innovation of "Pan-Engineering" in Engineering University. Journal of JiangSu Polytechnic University. 2006,7(3):35-38.

[2] YuYan Xia. Innovative Talents Training in Major of Mechanical Engineering Based on Idea of Largescale Engineering. The JiangSu University for the degree of Master of Philosophy, 2009:10-17.

[3] GV . Moskvitin . Problems of engineering education and production of young scientists. Allerton Press, Inc . distributed exclusively by Springer Science+Business Media LLC. 2008(5).

[4] Wei Zhang. A Comparative Study on the Engineering education of Five Countries-A Comparative Study Oil the Engineering of China and That of Four Western Countries and the Interaction between Engineering Education of the Five Countries and their Industrialization . Chinese Academy of Engineering. 2002. 